\title{
Ligation of patent ductus arteriosus in the very low birthweight newborn infant
}

\author{
R. W. I. COOKE, B. GRIBBIN, A. J. GUNNING, AND D. PICKERING \\ From the University Department of Paediatrics, John Radcliffe Hospital, and \\ Departments of Cardiology, Surgery, and Paediatrics, Radcliffe Infirmary, Oxford
}

SUMMARY Surgical closure of a patent ductus arteriosus was performed in 8 low birthweight infants suffering from cardiorespiratory failure secondary to a large left-to-right shunt. Mortality from the operation was nil, but only $4(50 \%)$ ultimately survived. Earlier intervention may reduce mortality in these high-risk infants.

The increasing frequency of patent ductus arteriosus (PDA) in neonatal special care units has produced an increased interest in methods of duct closure, in particular by the use of prostaglandin synthetase inhibitors such as indomethacin (Friedman et al., 1976; Heymann et al., 1976). However, complications from the use of such drugs have been recorded and other undesirable effects suggested as theoretical risks (Nadas, 1976). In our management of PDA we have largely confined therapy to conventional diuretic and digoxin therapy with respiratory support when required, and when this failed, surgical ligation. Infants affected are usually very immature and often have primary respiratory problems. Occasionally larger infants have PDA, but usually as a congenital cardiac abnormality. We report our experience with ligation of PDA in 8 infants, under $1500 \mathrm{~g}$ birthweight, during the period July 1975April 1977.

\section{Method}

Diagnosis of left-to-right shunt through a PDA was made on clinical grounds, by the presence of a characteristic systolic murmur with a wide pulse pressure, and accompanied by $x$-ray evidence of pulmonary plethora and usually an increase in diameter of the cardiac shadow (Jones and Pickering, 1976). If respiratory deterioration or cardiac failure occurred, conventional therapy with digoxin and frusemide was started. Constant positive airway pressure (CPAP) was usually used to treat the recurrent apnoea which almost always occurred (Roberton, 1974). In the event of further deterioration, surgical ligation of the PDA was carried out.

Received 3 October 1977

\section{Case reports}

Case 1. A female first twin was born at 28 weeks' gestation after premature labour and weighed $1100 \mathrm{~g}$. Hyaline membrane disease was apparent soon after delivery and was treated initially with continuous positive airways pressure by endotracheal tube and with $60 \%$ oxygen. Rapid deterioration occurred and intermittent positive pressure ventilation with $100 \%$ oxygen and peak airway pressures of up to $34 / 8 \mathrm{~cm} \mathrm{H}_{2} \mathrm{O}$ from 8 hours of life was used. Bilateral pneumothoraces occurred during the first $\mathbf{4 8}$ hours of life and were treated by thoracocentesis. Total intravenous and oral fluid intake reached $280 \mathrm{ml} / \mathrm{kg}$ per day. Multiple small blood transfusions were given in an attempt to correct initial hypotension, and later to maintain a falling haematocrit. There was a severe metabolic acidosis during the first 48 hours of life. Fits occurred at 20 hours and at 30 hours of age.

A slow improvement allowed the inspired oxygen to be reduced to $40 \%$ on the 4th day of life. Oliguria and generalised oedema occurred at 6 days of age, persisting until death, but did not respond to frusemide therapy and fluid restriction. A loud systolic murmur appeared on the 10th day. Total intravenous alimentation was started. Pulmonary plethora was noted on chest $x$-ray and an enlarging cardiac shadow was seen on the 13th day. No improvement was noted after further frusemide therapy and the PDA was ligated on the same day. Death occurred 24 hours later. Massive intraventricular haemorrhage was found post-mortem.

Case 2. A female twin (twin of Case 1) was born at 28 weeks' gestation after premature labour and weighed $1180 \mathrm{~g}$. There was no birth asphyxia. 
Hyaline membrane disease which developed soon after birth was treated with CPAP at a pressure of $5 \mathrm{~cm} \mathrm{H}_{2} \mathrm{O}$ from birth. The inspired oxygen was increased from $40 \%$ to $70 \%$ over the first 3 hours to maintain $\mathrm{PaO}_{2}$ above 60 torr as read from an indwelling umbilical oxygen electrode. At 3 hours of age ventilation with peak airway pressures of up to $30 / 4 \mathrm{~cm} \mathrm{H}_{2} \mathrm{O}$ with $70 \%$ oxygen was required following apnoea. Bilateral pneumothoraces occurred in the first 24 hours of life and were treated with thoracocentesis. Multiple small blood transfusions were used initially to correct hypotension and later to correct a falling haematocrit.

Pulmonary interstitial emphysema was noted on the 5th day and a persistent metabolic acidosis developed. Total intravenous and oral fluid intake reached $190 \mathrm{ml} / \mathrm{kg}$ per day before a loud systolic murmur appeared on the 6th day of life. Some improvement then occurred and by the 9th day she was maintained on CPAP at $6 \mathrm{~cm} \mathrm{H}_{2} \mathrm{O}$ in $40 \%$ oxygen. Increasing pulmonary plethora and cardiomegaly on $x$-ray were noted and ventilation was again required. On the 13th day the PDA was ligated after failure of digoxin and frusemide therapy. Rapid development of hydrocephalus, secondary to intraventricular haemorrhage which may have occurred preoperatively, caused death 7 days later.

Case 3. A female first twin, weighing $1080 \mathrm{~g}$, was born at 26 weeks' gestation, after spontaneous premature labour. The second twin died of severe birth asphyxia. Mechanical ventilation was started at 30 minutes of age because of apnoea and hypoxia in $100 \%$ oxygen. Maximum airway pressure of $28 / 2$ $\mathrm{cm}_{2} \mathrm{O}$ was used. A rapid improvement occurred. CPAP was begun at 14 hours and the infant was extubated and breathing $30 \%$ oxygen spontaneously at 24 hours of age. Apnoeic attacks began on the 3rd day of life, requiring ventilation again with pressures $17 / 0 \mathrm{~cm} \mathrm{H} \mathrm{H}_{2}$.

On the 4th day a loud systolic murmur with a wide pulse pressure was noted. Fluid intake was $160 \mathrm{ml} / \mathrm{kg}$ per day for 48 hours before the murmur appeared. Ventilatory support was continued with CPAP at $5 \mathrm{~cm} \mathrm{H}_{2} \mathrm{O}$, and intermittent periods of mechanical ventilation while breathing $25 \%$ oxygen. On the 13th day, tachycardia and hepatomegaly were noted, and a chest $x$-ray showed cardiomegaly and pulmonary plethora. Digoxin and frusemide were given for 4 days without improvement, and ligation of the PDA was carried out on the 17th day. Rapid clinical improvement occurred, although recovery was complicated by laryngeal stenosis secondary to tracheal intubation. Development has been normal to 18 months of age, although two episodes of croup have occurred, requiring hospital admission.
Case 4. A girl, weighing $1000 \mathrm{~g}$, was born after premature rupture of membranes at 26 weeks' gestation. She developed transitory respiratory difficulties in the first 24 hours and was treated with $30 \%$ oxygen. An exchange transfusion for hyperbilirubinaemia associated with prematurity was carried out on the 2nd day of life. Fluid intake by gavage feeding of breast milk was $190 \mathrm{ml} / \mathrm{kg}$ per day until the 10th day when it was increased to $200 \mathrm{ml} / \mathrm{kg}$ per day. Recurrent apnoea began from the 3rd day of life and did not respond to $25-30 \%$ inspired oxygen. Pulmonary plethora was seen on $x$-ray from the 10th day onwards. Fluid intake was increased to $240 \mathrm{ml} / \mathrm{kg}$ per day on the 15th day because of failure to gain weight.

A loud systolic murmur appeared 24 hours later. Digoxin therapy was started. A $12 \mathrm{ml}$ transfusion of blood was given on the 22nd day because of a low haematrocrit. The inspired oxygen concentration required to maintain a satisfactory $\mathrm{PaO}_{2}$ rose to $40 \%$ and later collapse with clinical signs of pulmonary oedema occurred on the 25th day. She was ventilated at a pressure of $24 / 0 \mathrm{~cm} \mathrm{H}_{2} \mathrm{O}$ for 12 hours. Ligation of the PDA on the following day caused dramatic improvement, although some airway obstruction due to laryngeal oedema delayed full recovery for 3 weeks. Development appears normal at 18 months of age.

Case 5. A male second twin, weighing $780 \mathrm{~g}$ at birth after 25 weeks' gestation, developed severe hyaline membrane disease from birth. Ventilation was required from birth until 5 weeks of age, with maximum peak airway pressures of $25 / 3 \mathrm{~cm} \mathrm{H}_{2} \mathrm{O}$. Initially $100 \%$ oxygen was required but it was possible to reduce this to $40 \%$ over the first week of life. Attempts at 'weaning' from ventilation with CPAP failed until 5 weeks of age when he was established on CPAP via an endotracheal tube. The endotracheal tube was removed at 8 weeks but he still required $40 \%$ oxygen. Multiple small blood transfusions were given to maintain the haematocrit above $40 \%$.

A loud systolic murmur was first heard at 28 days and full pulses together with pulmonary oedema on $x$-ray were noted. Recurrent apnoea delayed removal of CPAP for several weeks and persisted until 10 weeks. Fluid intake at the time the murmur appeared was $250 \mathrm{ml} / \mathrm{kg}$ per day as gavage fed breast milk. Treatment with digoxin and frusemide was ineffective. On echocardiography, LA/AO ratio at 8 weeks of age was $1 \cdot 4 / 1$, indicating a large left-toright shunt through a PDA. A single dose of indomethacin $(0.2 \mathrm{mg} / \mathrm{kg}$ orally) given at that time produced no improvement clinically. Ligation of the PDA at age 70 days produced no clinical improvement. In particular the oxygen requirement and 
frequency of apnoeic attacks remained unchanged. A lung biopsy at operation showed severe bronchopulmonary dysplasia. Death occurred 4 weeks later from progressive respiratory failure.

Case 6. A male second triplet, weighing $790 \mathrm{~g}$, was born at 25 weeks' gestation after premature rupture of membranes. Severe hyaline membrane disease required ventilation from 15 minutes until 3 days of age using peak airway pressure of $20 / 5 \mathrm{~cm} \mathrm{H}_{2} \mathrm{O}$ and up to $80 \%$ oxygen. Ventilatory support was continued from the 4th day for several weeks with CPAP and with intermittent ventilation when apnoea occurred. Inspired oxygen was kept between 35 and $40 \%$ as required. Fluid intake of intravenous dextrose and gavage fed breast milk as tolerated in the $\mathbf{4 8}$ hours before a loud systolic murmur appeared on the 7th day was $200 \mathrm{ml} \mathrm{kg}$ per day. Ventilatory support was increased because of recurrent apnoea on CPAP and a wide pulse pressure with pulmonary plethora on $x$-ray. Digoxin and frusemide were ineffective. Multiple small blood transfusions were given to maintain the haematocrit above $40 \%$. A single dose of indomethacin $(0.2 \mathrm{mg} / \mathrm{kg})$ on the 22nd day of life produced no clinical improvement.

After PDA ligation, in the 7th week, ventilatory support was reduced and eventually discontinued. This was delayed by a laryngeal stenosis, which later required tracheostomy at 13 weeks of age before extubation was possible. It was never possible to reduce the inspired oxygen to below $40 \%$. A slow decline into respiratory failure later occurred, and although death occurred from $E$. coli meningitis at 18 weeks of age, bronchopulmonary dysplasia was present at postmortem.

Case 7. A girl weighing $1050 \mathrm{~g}$ was born at 30 weeks' gestation after premature rupture of membranes. Increasingly frequent apnoeic episodes developed from 24 hours of age, despite an increased inspired oxygen of $40 \%$. Ventilation was required from 3 to 5 days of age at maximum airway pressures of $20 / 0 \mathrm{~cm} \mathrm{H}_{2} \mathrm{O}$. On the 5th day a change to CPAP with air at $5 \mathrm{~cm} \mathrm{H}_{2} \mathrm{O}$ pressure was possible, but a loud systolic murmur was later heard. Further clinical deterioration with a return to ventilation and an increased oxygen requirement led to ligation of the PDA on the 12th day. 3 days postoperatively the infant was breathing air spontaneously again. Some subsequent problems from laryngeal oedema occurred after extubation but she eventually did well.

Case 8. A boy weighing $1340 \mathrm{~g}$ was born at 32 weeks' gestation, by emergency caesarean section for severe pre-eclamptic toxaemia. Hyaline membrane disease developed, requiring mechanical ventilation from $4 \frac{1}{2}$ hours of age because of hypoxia and severe respiratory acidosis. After 12 hours ventilatory support was maintained with CPAP via a facemask at $3 \mathrm{~cm} \mathrm{H}_{2} \mathrm{O}$ pressure and an inspired oxygen of $60 \%$, until the 5 th day of life. The inspired oxygen was then gradually reduced until he was breathing in air spontaneously on the 7th day. A loud systolic murmur was first heard at 11 days of age. Fluid intake averaged $185 \mathrm{ml} / \mathrm{kg}$ per day for 48 hours before the murmur appeared. On the 21 st day tachypnoea, a wide pulse pressure, rib recession, and hepatomegaly were noted. Signs of cardiomegaly and pulmonary pressure were present on chest $x$-ray but were not marked. Treatment with digoxin and frusemide was started, but his condition deteriorated. On the 27th day of life, indomethacin $0.2 \mathrm{mg} / \mathrm{kg}$ orally was given 3 times at 12 -hour intervals. There was clinical evidence of a narrowing of the pulse pressure from $70 / 15$ to $80 / 40$ and of improved peripheral perfusion, but symptoms of cardiac failure persisted with fluid retention, and 48 hours later ligation of the PDA was carried out. His recovery was uneventful, with symptoms abating a few hours postoreratively, and development has been normal.

\section{Discussion}

Ligation of PDA in low birthweight infants has been practised for several years in North America (Horsley et al., 1973; Kitterman et al., 1972; Neal et al., 1975; Thibeault et al., 1975). We have found the procedure relatively simple and safe. No unusual problems were encountered and no mortality was directly attributable to surgery, which was carried out in an operating theatre close to the intensive care unit. Clinical features and outcome of each case are summarised in the Table.

There were 4 deaths. 2 infants (Cases 1 and 2) died of massive intraventricular haemorrhage and of hydrocephalus secondary to this, respectively. In retrospect both infants had probably developed cerebral complications before surgery, complications not uncommon in very low birthweight infants suffering from hyaline membrane disease. In 2 cases (Cases 5 and 6) ligation of PDA was delayed for 5 to 6 weeks in the hope that conventional therapy with digoxin and diuretics, and ventilatory support would succeed in allowing the PDA to close spontaneously as the infant matured. In both cases surgery was initially successful, but death ensued after several weeks from respiratory failure, associated with bronchopulmonary dysplasia, as a result of ventilation and chronic pulmonary oedema. In one case meningitis was the actual cause of death. 
Table Summary of clinical features and outcome of infants undergoing ligation of patent ductus arteriosus

\begin{tabular}{|c|c|c|c|c|c|c|c|c|}
\hline \multirow[t]{2}{*}{ Case no. } & \multirow[t]{2}{*}{ Early illness } & \multirow[t]{2}{*}{ Gestation (w) } & \multirow{2}{*}{$\begin{array}{l}\text { Birth- } \\
\text { weight }(g)\end{array}$} & \multicolumn{3}{|l|}{ Ductus } & \multirow[t]{2}{*}{ Died } & \multirow[t]{2}{*}{ Cause of death } \\
\hline & & & & $\begin{array}{l}\text { Murmur } \\
\text { heard }(d)\end{array}$ & Failure $(d)$ & $\begin{array}{l}\text { Ductus } \\
\text { tied }(d)\end{array}$ & & \\
\hline $\begin{array}{l}1 \\
2 \\
3 \\
4 \\
5 \\
6 \\
7 \\
8\end{array}$ & $\begin{array}{l}\text { HMD } \\
\text { HMD } \\
\text { Apnoea } \\
\text { Apnoea } \\
\text { HMD } \\
\text { HMD } \\
\text { Apnoea } \\
\text { HMD }\end{array}$ & $\begin{array}{l}28 \\
28 \\
26 \\
26 \\
25 \\
25 \\
30 \\
32\end{array}$ & $\begin{array}{r}1100 \\
1180 \\
1080 \\
1000 \\
760 \\
790 \\
1050 \\
1340\end{array}$ & $\begin{array}{r}10 \\
6 \\
4 \\
16 \\
28 \\
7 \\
5 \\
11\end{array}$ & $\begin{array}{r}13 \\
8 \\
13 \\
20 \\
28 \\
8 \\
9 \\
21\end{array}$ & $\begin{array}{l}13 \\
13 \\
17 \\
26 \\
70 \\
46 \\
11 \\
29\end{array}$ & $\begin{array}{l}14 \\
21 \\
\text { Alive } \\
\text { Alive } \\
98 \\
127 \\
\text { Alive } \\
\text { Alive }\end{array}$ & $\begin{array}{l}\text { IVH } \\
\text { Hydrocephalus, IVH }\end{array}$ \\
\hline
\end{tabular}

HMD = hyaline membrane disease; IVH = intraventricular haemorrhage $;$ BPD=bronchopulmonary dysplasia.

Earlier intervention in these 2 cases may have allowed survival by avoiding lung damage (Nelson et al., 1976). In the 4 long-term survivors the initial diagnosis was hyaline membrane disease in only 1 infant, despite their immaturity. In the other 3 infants frequent apnoeic attacks occurred from the first 24 hours of life, increasing in severity until clear symptoms of PDA became evident. Failure of medical treatment and rapid deterioration while being ventilated made ligation advisable. Marked improvement occurred after surgery and recovery was complete.

Other centres have had a similar success rate in duct ligation in this age group but have been less conservative in their approach (Edmunds et al., 1973; Gay et al., 1973; Nelson et al., 1976). The infants treated by duct ligation in these series were mostly suffering from hyaline membrane disease, although we have found ligation necessary in 3 infants suffering from apnoea of prematurity alone. The apnoeic attacks may, however, have represented early symptoms of pulmonary oedema.

C. McMurphy and co-workers (1972) have shown that the sensitivity of the isolated fetal lamb ductus arteriosus to oxygen is related to gestational age. Increased survival of preterm infants may contribute to the increase of PDA particularly if through illness their arterial oxygen saturation is low. Although all of the infants in this series suffered from hypoxia at some time, they were usually well oxygenated. Although hypoxia may be an important factor in the maintenance of PDA in human infants, it is not likely to be the only one. The rapid apparent increase in incidence in PDA in the last few years in some centres, and its relative scarcity in others, suggests some iatrogenic factor. The introduction of high volume feeds, multiple blood transfusions, constant positive airway pressure, together with increased survival of low birthweight infants have all paralleled this increase in PDA. Stevenson (1977) suggested that high fluid intake may have contributed to the rise in PDA seen in his experience. All the infants in this study were given high volume feeds, either to avoid dehydration under overhead heaters (Jones et al., 1976) or to increase caloric intake in order to promote growth. Blood transfusion in the critically ill infant could lead to hypervolaemia and the occurrence of PDA in a similar way as a high fluid intake. We have used small blood transfusions to counteract hypotension and metabolic acidosis, and CPAP in the treatment of hyaline membrane disease and apnoea of prematurity in high-risk infants for several years, and so no control data are available making the role of these therapies, if any, in the aetiology of PDA difficult to assess.

The introduction of simple drug therapy for PDA in the form of indomethacin or other prostaglandin synthetase inhibitors with a more specific action on the ductus arteriosus may make the decision to treat PDA easier than if one has to decide to subject a sick infant to surgery. However, the side effects of such drug therapy in the newborn period are still largely unexplored (Nadas, 1976). On the other hand, surgical ligation is safe. It will probably remain the standard mode of therapy in low birthweight infants when cardiorespiratory failure occurs secondary to a large left-to-right shunt through a PDA, at least until pharmacological methods of duct closure are fully explored.

R.W.I.C. is supported by a grant from the Sir William Coxen Trust.

\section{References}

Edmunds, L. H., Jr., Gregory, G. A., Heymann, M. A. Kitterman, J. A., Rudolph, M. A., and Tooley, W. H. (1973). Surgical closure of the ductus arteriosus in premature infants. Circulation, 48, 856-863.

Friedman, W. F., Hirschklau, M. J., Printz, M. P., Pitlick, P. T., and Kirkpatrick, S. E. (1976). Pharmacologic closure of patent ductus arteriosus in the premature infant. New England Journal of Medicine, 295, 526-529.

Gay, J. H., Daily, W. J. R., Meyer, B. H. P., Trump, D. S., Cloud, D. T., and Molthan, M. E. (1973). Ligation of patent ductus arteriosus in premature infants: report of 45 cases. Journal of Pediatric Surgery, 8, 677-683. 
Heymann, M. A., Rudolph, A. M., and Silverman, N. H. (1976). Closure of the ductus arteriosus in premature infants by inhibition of prostaglandin synthesis. New England Journal of Medicine, 295, 530-533.

Horsley, B. L., Lerberg, D. B., Allen, A. C., Zuberbuhler, J. R., and Bahnson, H. T. (1973). Respiratory distress from patent ductus arteriosus in the premature newborn. Annals of Surgery, 177, 806-810.

Jones, R. W. A., and Pickering, D. (1977). Persistent ductus arteriosus complicating the respiratory distress syndrome. Archives of Disease in Childhood, 52, 274-281.

Jones, R. W. A., Rochford, M. J., and Baum. J. D. (1976). Increased insensible water loss in newborn infants under radiant heaters. British Medical Journal, 2, 1347.

Kitterman, J. A., Edmunds, L. H., Jr., Gregory, G. A., Heymann, M. A., Tooley, W. H., and Rudolph, A. M. (1972). Patent ductus arteriosus in premature infants, incidence, relation to pulmonary disease and management. New England Journal of Medicine, 287, 473.

McMurphy, D. M., Heymann, M. A., Rudolph, A. M., and Melmon, K. L. (1972). Developmental changes in constriction of the ductus arteriosus: responses to oxygen and vasoactive agents in the isolated ductus arteriosus of the fetal lamb. Pediatric Research, 6, 231-238.

Nadas, A. S. (1976). Patent ductus revisited. New England Journal of Medicine, 295, 563-564.
Neal, W. A., Bessinger, F. B., Jr., Hunt, C. E., and Lucas, R. V., Jr. (1975). Patent ductus arteriosus complicating respiratory distress syndrome. Journal of Pediatrics, 86, 127-131.

Nelson, R. J., Thibeault, D. W., Emmanouilides, G. C., and Lippmann, M. (1976). Improving the results of ligation of patent ductus arteriosus in small pre-term infants. Journal of Thoracic and Cardiovascular Surgery, 71, 169178.

Roberton, N. R. C. (1974). Prolonged continuous positive airways pressure for pulmonary oedema due to persistent ductus arteriosus in the newborn. Archives of Disease in Childhood, 49, 585-587.

Stevenson, J. G. (1977). Fluid administration in the association of patent ductus arteriosus complicating respiratory distress syndrome. Journal of Pediatrics, 90, 257-261.

Thibeault, D. W., Emmanouilides, G. C., Nelson, R. J., Lachman, R. S., Rosengart, R. M., and Oh, W. (1975). Patent ductus arteriosus complicating the respiratory distress syndrome in preterm infants. Journal of Pediatrics, 86, 120-126.

Correspondence to Dr R. W. I. Cooke, University Department of Paediatrics, John Radcliffe Hospital, Headington, Oxford OX3 9DU. 